\title{
Occupational Eye Lens Radiation Dose While Performing Interventional Procedures over 18 Months Using a Face-Shield Equipped Suspended Radiation Protection System
}

\author{
Thomas J. Kwarcinski, Andrew Lichliter, Joseph Oros, Niraj KC, Bryan Yoder, Chet R. Rees \\ Department of Radiology, Baylor University Medical Center, Dallas, TX, USA \\ Email: Thomas.Kwarcinski@BSWHealth.org
}

How to cite this paper: Kwarcinski, T.J., Lichliter, A., Oros, J., KC, N., Yoder, B. and Rees, C.R. (2020) Occupational Eye Lens Radiation Dose While Performing Interventional Procedures over 18 Months Using a Face-Shield Equipped Suspended Radiation Protection System. Open Journal of Radiology, 10, 101-114.

https://doi.org/10.4236/ojrad.2020.102011

Received: April 29, 2020

Accepted: June 15, 2020

Published: June 18, 2020

Copyright $\odot 2020$ by author(s) and Scientific Research Publishing Inc. This work is licensed under the Creative Commons Attribution International License (CC BY 4.0).

http://creativecommons.org/licenses/by/4.0/

\begin{abstract}
Background: Numerous studies have demonstrated increasing evidence for cataractogenesis at lower levels of ionizing radiation than previously believed, with some suggesting possible absence of a threshold. Genetic differences between individuals also result in increased susceptibility in some operators, who might not be aware. European occupational exposure limits have been reduced and operators are seeking protective measures. Objective: To evaluate the protective effect of a face-shield equipped suspended protection system (Zero-Gravity ${ }^{\circledR}$, TIDI Products, Neenah, WI) along with adherence to safety practices against radiation dose to the eye lens for an interventional radiologist performing a wide variety of procedures. Materials and Methods: In this institutional review board-approved single-institution study, one interventional radiologist wore a highly sensitive personnel monitoring dosimeter badge on the cap near the left eye while performing 299 procedures (3690 fluoroscopy minutes) over 18 consecutive months while utilizing the suspended protection system along with adherence to other generally recommended safety practices and movement away from the field during angiographic power injections. Dosimetry reports and procedural information were retrospectively reviewed. Results: Total lens dose equivalent to the left eye over 18 months was $0.11 \mathrm{mSv}$ (annualized dose $=0.073 \mathrm{mSv}$, or 7.3 $\mathrm{mRem}$ ). The patient-dose-area product standardized dose of $0.00576 \mu \mathrm{Sv} / \mathrm{Gy} \cdot \mathrm{cm}^{2}$ is well below reports of conventional lead aprons, shields, and protective eyewear. Conclusion: Eye exposures were kept to near-background levels using the materials and methods of this study while performing a wide variety of complex procedures from all positions around the patient.
\end{abstract}




\section{Keywords}

Lens Dose Reduction, Radiation Safety, Radiation-Induced Cataractogenesis, Suspended Protection System

\section{Introduction}

Many studies have suggested that based on epidemiological evidence, cataracts may occur following exposure to lower doses of ionizing radiation than previously believed and may occur in a stochastic manner [1] [2] [3] [4]. Genetic predispositions such as defects of repair genes complicate the establishment of effective safety guidelines, which currently presume radiation sensitivity homogeneity among different populations [5]. Consequently, in 2012 the International Commission on Radiological Protection (ICRP) revised threshold absorbed dose for radiation-induced cataracts to $0.5 \mathrm{~Gy}$ for prolonged or acute exposure and markedly reduced the annual occupational exposure limit from 15,000 mrem $(150 \mathrm{mSv})$ to $2000 \mathrm{mrem}(20 \mathrm{mSv})$ averaged over 5 years, with no single year exceeding $50 \mathrm{mSv}$ [1]. The European Union (EU) responded to the new ICRP recommendation by incorporating the new dose limits into the current European basic safety standard, while in the United States the National Council on Radiation Protection and Measurements (NCRP) has not advocated a reduction from the 7.5 fold higher annual limit of 15,000 mrem (150 mSv) [6] [7].

This information has led interventional radiologists, interventional cardiologists and radiological technologists to revisit protective measures to combat radiation-induced cataractogenesis [4] [5] [8] [9]. A 2015 study concluded that any lens exposure may have associated cataract risk and suggested that interventional radiology work increases probability of cataract development [9]. Employing protective measures such as leaded glasses, patient-supported protective blankets, and suspended ceiling shields have shown to reduce lens doses [7]. However, these measures are not always achieved in practice, and multiple studies have revealed that the occupational exposure limit may still be exceeded [8] [10] [11] [12] [13]. One study showed the exposures to the lenses to be higher than any other tissue of the head and neck when unprotected [14].

Lead glasses provide incomplete protection due to the incident angles of scatter radiation during clinical use, as well as substantial secondary scatter from the tissues of the head and neck [14] [15] [16] [17] [18]. Dose reductions of 44\%, $53 \%$, and $27 \%-62 \%$ for the tube-side eye were shown in three different studies of many types of lead glasses and various tube angles [15] [16] [17]. Reductions to the contralateral (typically the right) eye were $0 \%-12 \%$ due to unfavorable geometry [14] [16]. A thin $0.1 \mathrm{~mm} \mathrm{~Pb}$ equivalent head-supported partial face shield outperformed all lead glasses of $0.75 \mathrm{~mm}$ equiv, showing the importance of extremely broad coverage of the eyes and surrounding tissues from very wide angles [18]. The importance of scatter geometry was also demonstrated in a 
study of radioprotective surgical caps, which showed only a 3.3\% reduction in brain dose due to incident angles [16].

Concurrent use of other shields is generally recommended to supplement lead glasses [15] [16] [18] [19]. Mobile lead-acrylic shields provide dose reduction to the eyes of approximately $56 \%$ when used in a variety of projections and geometries [19]. Protection is variable due in part to differences in how they are used and limitations of their positioning during work which sometimes preclude their use [18] [20]. When using SPS, the authors recommend using the mobile leadacrylic shield when available and not cumbersome, in keeping with the principles of ALARA (as low as reasonably achievable) and to reduce exposure to the secondary operator and circulating personnel. Lead glasses are generally not used at the study institution when using SPS due to the low ocular exposures demonstrated, however they have been considered at other institutions with different experiences [21]. Users of SPS may estimate their own ocular exposures by wearing their "collar" badge on the cap near the eye as described in this study, in compliance with standard practice.

A suspended personal radiation protection system (SPS) (Zero-Gravity ${ }^{\circledR}$, TIDI Products, Neenah WI) has shown improved radiation protection for multiple body parts including the eye compared to conventional lead-apron with mobile suspended leaded-acrylic shields [21]-[27]. The purpose of this study was to evaluate the protective effect of a face-shield equipped SPS along with adherence to safety practices against radiation dose to the eye lens for an interventionalist performing a variety of procedures.

\section{Methods}

\subsection{Study Design}

IRB-approved retrospective review of dosimetry reports and corresponding procedural technical information was performed corresponding to a consecutive 18-month period (March, 2016 through August, 2017) for a single interventional radiologist at a large teaching institution. The operator wore the institution's standard personnel-monitoring dosimeter during all procedures included in this study. Although generally worn at the collar by most personnel, the study operator wore theirs near their left eye as detailed below. The operator performed the standard procedures and duties as an attending physician and full-time interventionalist working weekdays and on call.

This study includes all the results of the dosimeters worn by the study operator when using the SPS during the study period. The procedures represent all consecutive cases performed by the operator using the SPS at the single institution. Only one SPS was available in the procedure room, and generally it is used by the primary operator since they are closest to the scatter source. For simpler procedures where the trainee was expected to occupy the primary operator position, the trainee used SPS while the study operator used a conventional lead apron. Although not quantified, this was a minority of procedures. More com- 
monly when working with a trainee, the study operator used the SPS and assumed the primary position, occasionally stepping over into secondary position while still using SPS for a minority but unquantified proportion of the procedure. The operator had separate dosimeters for use with conventional lead aprons, and only the results of the dosimeters used with SPS are included in this study. Therefore, this study reports all eye lens dose received by the study operator for all procedures using SPS over the 18-month period, with corresponding fluoroscopy times and patient dose information.

A ceiling-mounted mobile lead-acrylic shield (Mavig, Munich, Germany) was used according to operator preference when possible or not cumbersome. An under-table leg shield on the right side of the table was permanently present in all procedures, however it provided no protection for the operator when standing at the head or on the left side of the patient. Lead eyeglasses and patientsupported attenuating pads were not used.

The operator performed the listed procedures in their standard ways without any changes related to the study. Operator position relative to the patient and equipment was the same as it would have been if using a conventional lead apron, varying according to procedure type and not specifically recorded. When possible, patients were positioned to prevent positioning of the operator on the left side of the table where mobile and table shields were not present.

It is the general practice at the study site to move away from the radiation field to a location behind a leaded wall during imaging series acquisitions utilizing a power injector in order to further reduce occupational exposures as reported by Layton et al. [28]. This practice was facilitated by the magnetic attachment system of the SPS as demonstrated in Figure 1, which allows rapid engagement and disengagement while remaining sterile.

\subsection{Device Descriptions}

The SPS included a $1 \mathrm{~mm}$ lead apron and a $0.5 \mathrm{~mm} \mathrm{~Pb}$-acrylic face-shield encompassing an arc covering the front and sides of the operator's head. The interventionalist wore a lightweight fabric mesh vest which magnetically connected to the SPS at the appropriate height to maintain its constant position relative to the operator's head and body as seen in Figure 1. The device moved in all three spatial planes with the operator, who magnetically engaged or disengaged as needed, while maintaining sterile field.

The imaging unit was a single-plane Philips Allura FD-20 fixed C-arm X-ray system (Philips Healthcare, Best, Netherlands). The dosimeters (Optically Stimulated Luminescence, Luxel ${ }^{\circledR}+$, Landauer, Glenwood, IL) were positioned adjacent to the left eye, on the head cap (Figure 1), at the point of maximum exposure where it is closer to the scatter source for most procedures [10]. The dosimeters were standard at the institution during the study period for all personnel at risk of exposure, and were handled in the standard manner, changed monthly, and delivered to the manufacturer along with controls for subtraction 


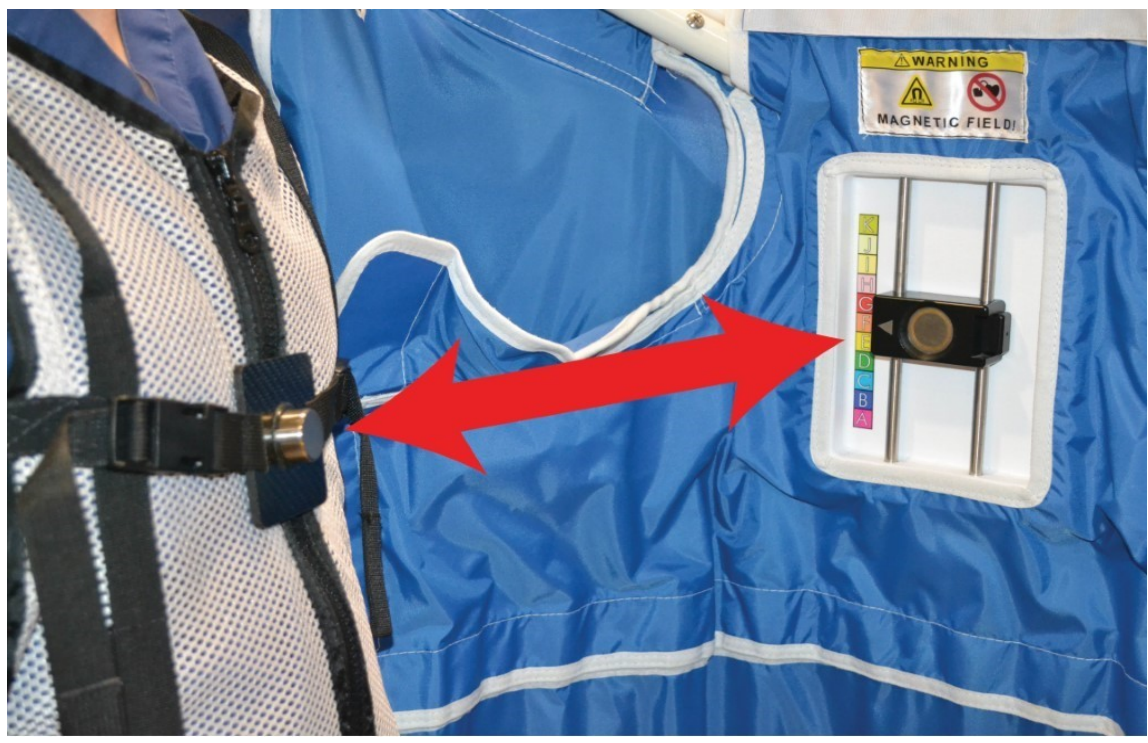

(a)

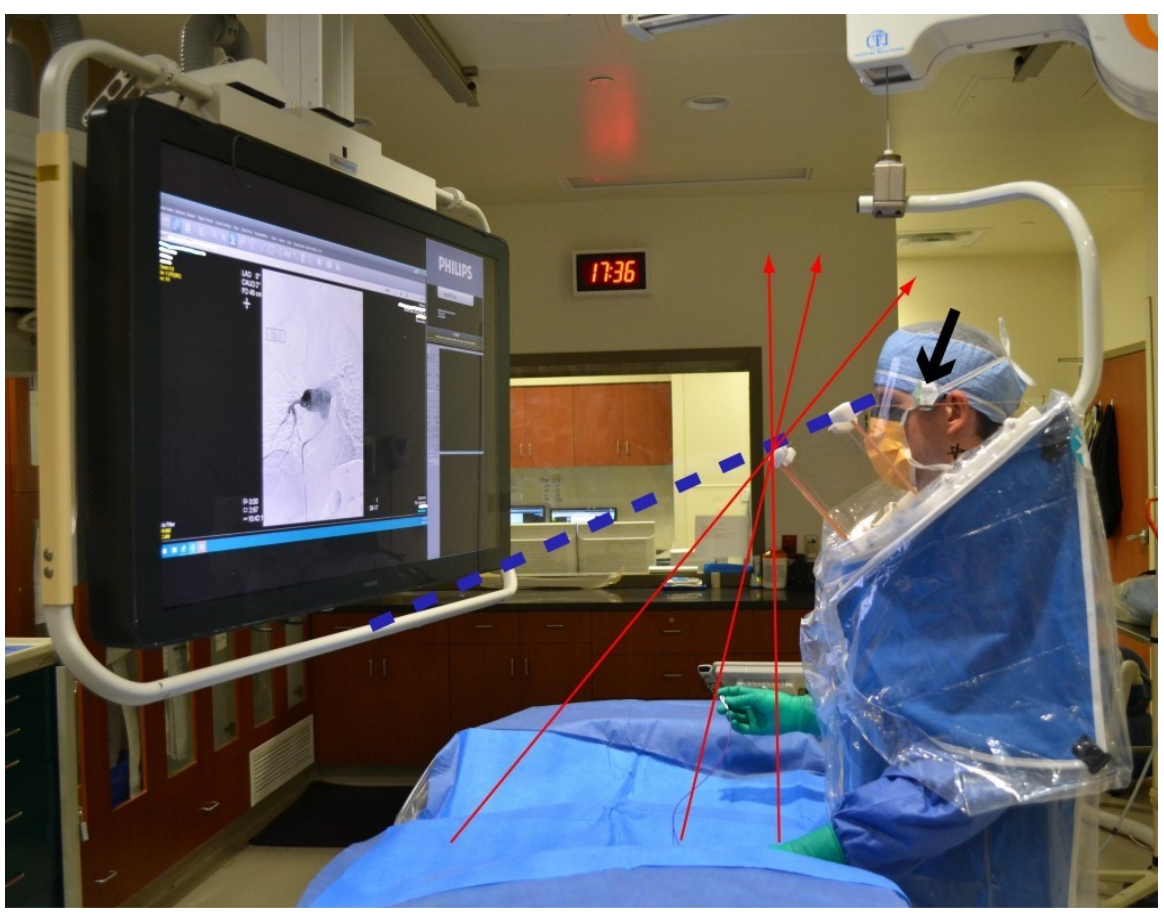

(b)

Figure 1. (a) The operator is using SPS while wearing dosimeter near the eye (short arrow). The top of the face-shield is positioned immediately below the line of site (dashed lines) with the monitor, permitting clear view while shielding the head from the upward-directed scatter field (long arrows). (b) The steel strike-disc on the light-weight vest will attach to the magnet on the SPS (double arrow) through the gown and drape. Each user may adjust the heights of the magnet on the SPS, and the strike-disc on the vest to provide optimum shield height. Suspension of the unit was adjusted to prevent sag.

of background according to manufacturer methods. The manufacturer maintained a valid NVLAP accreditation to demonstrate the validity of the measurements. According to the manufacturer's published specifications, the badge has a 
minimum reportable dose of $1 \mathrm{mrem}(10 \mu \mathrm{Sv})$, and a precision of $\pm 2 \mathrm{mrem}(20$ $\mu$ Sv) [29].

\subsection{Procedures}

A wide variety of vascular diagnostic, vascular interventional, and non-vascular interventional procedures were performed as summarized in Table 1. No procedures were excluded due to inability to use the SPS for a procedure or a portion of a procedure, as the SPS could be used for the entirety of all the types of procedures.

\subsection{Dose-Reduction Practices}

The subject attempted to practice according to widespread recommendations regarding patient and operator dose reductions through optimization of selectable controls such as image magnification, collimation, pulsed fluoroscopy, use of lower dose settings when feasible, minimization of fluoroscopy duration, and attention to table height and source-to-receptor distance [30] [31]. Most vascular imaging acquisitions were at $2-3$ frames per second, with a minority being higher or lower. X-ray tube outputs are automatically determined by the unit depending on operator-selected variables and specified patient body part.

\subsection{Outcomes Assessed}

Fluoroscopy time, total patient dose-area-product (DAP), and fluoroscopic

Table 1. Procedures comprising the study by type $(\mathrm{N}=299)$.

\begin{tabular}{|c|c|}
\hline Type of Procedure & $\mathrm{N}$ \\
\hline Chemoembolization, radio-embolization & 39 \\
\hline Transjugular Porto-Systemic Shunt placement or revision & 8 \\
\hline Transjugular liver biopsy with or without pressure measurements & 23 \\
\hline $\begin{array}{l}\text { Genitourinary (nephrostomy, nephrostomy exchange, } \\
\text { ureteral stent, suprapubic catheter placement) }\end{array}$ & 37 \\
\hline Biliary interventions & 34 \\
\hline IVC filter placement or retrieval & 21 \\
\hline Gastrostomy and related interventions & 9 \\
\hline Splenic artery embolization, spleno-renal shunt embolization & 13 \\
\hline Gastrointestinal angiography, embolization, or vascular stent placement & 19 \\
\hline Abscess drainage or tube manipulation & 15 \\
\hline Hepatic angiography, hepatic artery stent, hepatic embolization & 27 \\
\hline Renal angiography or embolization & 6 \\
\hline Endoleak interventions procedures including trans-lumbar embolization & 10 \\
\hline Tunneled central venous catheter placement & 6 \\
\hline Extremity angiography or vascular intervention & 8 \\
\hline Miscellaneous (embolization, venous sampling, fiducials, venograms, other) & 24 \\
\hline
\end{tabular}


dose-area product (fDAP, defined below) values were obtained from the imaging equipment reports for each procedure. Results for operator eye exposure are reported as deep dose equivalent (DDE) and lens dose equivalent (LDE), as provided by the manufacturer's monthly reports. The sums of values were used to provide standardized doses (LDE/DAP, DDE/DAP) in the manner of most reports of occupational eye exposure [8] [20] [21] [23] [32]-[39]. Standardization to DAP is described as the most effective and accepted method to report operator exposures [33] [34] [40]. Standardization to fDAP, corresponding to the patient DAP obtained only during fluoroscopy and not during serial image acquisitions, is also reported in this study due to the practice of movement away from the radiation field during imaging acquisition in the interventional radiology department of the study institution.

\subsection{Comparison to Background Radiation}

Background exposures at the study institution are not available since the manufacturer uses this information to calculate above-background doses without providing the background readings to the user, as per industry standard. Estimation is therefore based on reported values of annual background exposure to the average U.S. individual of 320 mrem whole-body effective dose, or $80 \mathrm{mrem}$ (800 $\mu \mathrm{Sv})$ without radon [41]. We are not aware of data specifically showing background population lens dose.

\section{Results}

Two hundred and ninety-nine vascular and non-vascular procedures of the chest, abdomen, pelvis, and extremities were performed over 18 months, as detailed in Table 1. Arterial vascular procedures were performed via femoral access with uncommon exceptions. Procedures performed from the head of the table, which are associated with higher exposures than standing at the patient's side, included transjugular intrahepatic portosytemic shunts, trans-jugular liver biopsies, IVC filter retrievals, and line placements [27]. A minority of body interventions were performed from the left side of the table which lacked mobile or table-mounted shields. The study included several biliary and abdominal interventional procedures, which are shown to be associated with higher operator exposures [32].

Cumulative DDE and LDE to the eye over 18 months were both 11 mrem (0.11 mSv). Cumulative fluoroscopy duration was 3690 minutes (61.5 hours), cumulative patient-DAP was $19,093 \mathrm{~Gy} \cdot \mathrm{cm}^{2}$, and cumulative patient-fDAP was $7663 \mathrm{~Gy} \cdot \mathrm{cm}^{2}$.

LDE standardized to patient DAP was $0.00576 \mu \mathrm{Sv} / \mathrm{Gy} \cdot \mathrm{cm}^{2}$. LDE standardized to month, year, fluoroscopy minutes, and patient fDAP were, respectively: 6.1 $\mu \mathrm{Sv}(0.61 \mathrm{mRem})$ per month, $73.2 \mu \mathrm{Sv}(7.32 \mathrm{mRem})$ per year, $0.03 \mu \mathrm{Sv}$ per fluoroscopy minute, and $0.01435 \mu \mathrm{Sv}$ per $\mathrm{Gy} \cdot \mathrm{cm}^{2}$.

Comparisons to available studies of operator eye dose standardized to patient 
DAP are depicted in Figure 2, which includes interventional cardiology, interventional neuroradiology, and interventional radiology centers. Comparing to studies using conventional lead aprons combined with mobile acrylic shield (all 14 studies) and lead glasses (6 studies), the DAP standardized dose in the current study of $0.00567 \mu \mathrm{Sv} / \mathrm{Gy} \cdot \mathrm{cm}^{2}$ was $<1 \%$ of the mean of those with conventional shields (mean $=0.987$, median $=0.830$ ), and $3.8 \%$ of the lowest of the comparison studies (range $=0.153$ to $3.37 \mu \mathrm{Sv} / \mathrm{Gy} \cdot \mathrm{cm}^{2}$ ) [8] [10] [20] [21] [23] [32]-[39] [42]. Annualized eye dose was $0.1 \%$ to $15 \%$ of those reports that included this information (range $=0.5-71.6 \mathrm{mSv} /$ year) [8] [20] [33] [35] [38] [43].

DAP standardized dose was also considerably lower than with the radioprotective cabin $\left(0.421 \mu \mathrm{Sv} / \mathrm{Gy} \cdot \mathrm{cm}^{2}\right)$, and slightly lower than 2 other studies of SPS (0.017 and $\left.0.123 \mu \mathrm{Sv} / \mathrm{Gy} \cdot \mathrm{cm}^{2}\right)$ [21] [23] [39]. Compared to the reported background dose without radon, the operator received an additional $9 \%$ of background due to the study exposure [41].

\section{Discussion}

This study demonstrated very large reductions in lens doses compared to clinical

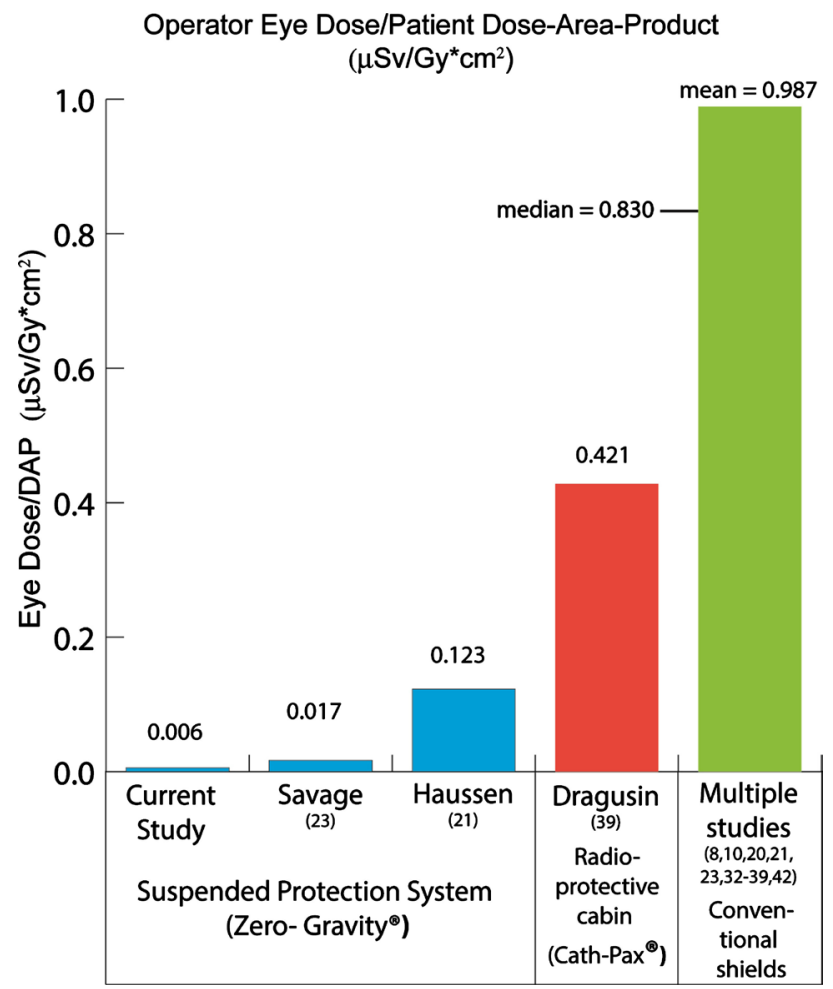

Figure 2. Operator eye dose standardized to patient DAP for the current study and other available reports. Current study and Savage et al. used the SPS for interventional radiology, Haussen et al. used the SPS for interventional neuroradiology with biplane fluoroscopy, Dragusin et al. used a radio-protective cabin for interventional cardiology, and the value on the far right represents the mean and median for available studies of interventional cardiology, interventional radiology, and interventional neuroradiology using conventional mobile lead-acrylic shields in all studies [8] [10] [20] [21] [23] [32]-[39] [42] and leaded glasses in some studies [8] [10] [33] [37] [38] [42]. 
reports of conventional shields and lead glasses. The resultant eye dose was only $9 \%$ above background, and only $0.4 \%$ of the annual occupational limit in the EU, so the operator could not realistically perform enough procedures under similar circumstances to approach the limit.

These results were achieved with the use of the SPS, the practice of moving out of the radiation field during power injected image sequence acquisitions, and careful attention to operator-controlled machine variables and other basic radiation protection methods [30] [31]. The important impact of the SPS is evident when comparing the great differences between the reports of SPS compared to all other shielding methods as demonstrated in Figure 2. The impact of moving out of the field during power injections depends on the proportion of the procedures performed by the operator where this is feasible, since it may be very useful with many vascular procedures but of little or no use on non-vascular procedures. In our study, the substantial difference between patient DAP vs. patient fDAP suggests that this practice should have had considerable impact. Of note, lens dose standardized to fDAP in this study was still far lower than lens dose standardized to DAP in non-SPS studies, further suggesting a large protective impact of using SPS.

Eye doses in this study were slightly lower than other SPS reports [21] [23]. Factors known to impact operator exposure which might have contributed to differences between SPS studies include careful attention to use of the magnetic vest and proper fitting to maintain the shield height at the optimal locations (Figure 1), as well as known factors such as frequency of use of biplane or lateral projections, settings of operator-selectable controls, patient size, location and type of dosimeter, types of procedures performed, and the practice of leaving the area during power-injected acquisitions [20] [27] [28] [30] [31]. Whereas one of the SPS studies used bi-plane fluoroscopy and imaging frequently, the current study was performed in a single plane room [21].

The SPS provides effective eye protection due to its constant geometric orientation relative to the user, with a face-shield that extends at least partially towards the side of the head and is contiguous with the lead apron, creating a consistent barrier to the upward-directed scatter in the interventional suite [44]. Prior to the development of SPS, a similar gap-free protection of the head and eyes was provided by a face-shield which was supported by the chest and shoulders of the operator and was shown to provide significantly improve protection of the eye and head tissues compared to conventional aprons and lead glasses; however, it did not gain widespread use most likely due to the burden of weight on the user [45]. Since the scatter radiation reaching the operator's head is predominantly arising from the patient below, the face-shield and contiguous apron must extend below the head and neck, and the top of the shield does not need to extend as high as the crown of the head to provide optimal protection to the entire head [44]. A properly fitted face-shield not only prevents geometric gaps in protection of the eyes from the primary scatter radiation, but additionally pro- 
tects the head and neck, reducing secondary scatter to the eyes from those tissues [45].

The positioning of the dosimeter in this study is consistent with the guidelines of manufacturer-specified use, and according to ICRP and state recommendations [29] [46] [47]. State Regulations require the positioning of the dosimeter at the estimated location of the highest whole-body exposure, not necessarily at the collar where it is often convenient [46]. The SPS provides wider protection compared to a lead apron so measurement of exposure above the lead drape is reasonable. Manufacturer reported deep dose equivalent (DDE), lens dose equivalent (LDE) and shallow dose equivalent (SDE) are simply related to the defined depth of measurement in tissue which is $10 \mathrm{~mm}, 3 \mathrm{~mm}$, and $0.07 \mathrm{~mm}$ respectively. Personal dosimeters have been shown to be satisfactory for the detection of scattered X-ray fields in interventional radiology and cardiology [48]. The revised ICRP $20 \mathrm{mSv}$ annual limit to the eye is based on equivalent dose, which is not directly measurable within the exposed individual [49]. Personal dose equivalent $\mathrm{Hp}$ at a depth of $3 \mathrm{~mm}$, corresponding to the radiation sensitive lens epithelium, is used for monitoring eye exposures in radiation workers, and may be measured with dosimeters designed to measure Hp for skin dose [50]. LDE is the most appropriate operational quantity to monitor eye lens dose [50] [51].

The study is limited to one operator at a single institution whose procedural case mix, protection methods, equipment, and patient populations may differ from others in ways that could affect their eye exposures.

\section{Conclusions}

- Lens cataracts may occur following exposure to lower doses of ionizing radiation dose to the eye than previously believed.

- Consequently, the ICRP revised threshold absorbed dose for radiation-induced cataracts.

- Interventional workers have revisited protective measures to the eye lens to combat radiation-induced cataractogenesis.

- The findings from this study show that proper fit and use of the SPS combined with avoidance of unnecessary exposure and adherence to standard safety practices make it possible to reduce radiation dose to the eye lens to near-background doses.

\section{Disclosure}

Dr. Rees receives personal fees from Interventco, LLC (Dallas, TX) which receives royalties from a relevant patent. No funding or encouragement was provided from Interventco, LLC in the writing of this paper.

\section{Conflicts of Interest}

The authors declare no conflicts of interest regarding the publication of this paper. 


\section{References}

[1] Stewart, F.A., Akleyev, A.V., Hauer-Jensen, M., et al. (2012) ICRP Publication 118: ICRP Statement on Tissue Reactions and Early and Late Effects of Radiation in Normal Tissues and Organs-Threshold Doses for Tissue Reactions in a Radiation Protection Context. Annals of the ICRP, 41, 1-322. https://doi.org/10.1016/j.icrp.2012.02.001

[2] Chodick, G., Bekiroglu, N., Hauptmann, M., et al. (2008) Risk of Cataract after Exposure to Low Doses of Ionizing Radiation: A 20-Year Prospective Cohort Study among US Radiologic Technologists. American Journal of Epidemiology, 168, 620-631. https://doi.org/10.1093/aje/kwn171

[3] Kleiman, N., Cabrera, M., Duran, G., Ramirez, R., Duran, A. and Vano, E. (2009) Occupational Risk of Radiation Cataract in Interventional Cardiology. Investigative Ophthalmology \& Visual Science, 49, 4553.

[4] Vano, E., Kleiman, N.J., Duran, A., Rehani, M.M., Echeverri, D. and Cabrera, M. (2010) Radiation Cataract Risk in Interventional Cardiology Personnel. Radiation Research, 174, 490-495. https://doi.org/10.1667/RR2207.1

[5] Khan, D.Z., Lacasse, M.C., Khan, R. and Murphy, K.J. (2017) Radiation Cataractogenesis: The Progression of Our Understanding and Its Clinical Consequences. Journal of Vascular and Interventional Radiology, 28, 412-419. https://doi.org/10.1016/j.jvir.2016.11.043

[6] Barnard, S.G., Ainsbury, E.A., Quinlan, R.A. and Bouffler, S.D. (2016) Radiation Protection of the Eye Lens in Medical Workers-Basis and Impact of the ICRP Recommendations. The British Journal of Radiology, 89, Article ID: 20151034. https://doi.org/10.1259/bjr.20151034

[7] Dauer, L.T., Hamada, N. and Blakely, E.A. (2017) National Council on Radiation Protection and Measurements Commentary Number 26: Impact of Revised Guidance on Radiation Protection for the Lens of the Eye. Journal of the American College of Radiology, 14, 980-982. https://doi.org/10.1016/j.jacr.2017.05.003

[8] O'Connor, U., Walsh, C., Gallagher, A., et al. (2015) Occupational Radiation Dose to Eyes from Interventional Radiology Procedures in Light of the New Eye Lens Dose Limit from the International Commission on Radiological Protection. The British Journal of Radiology, 88, Article ID: 20140627. https://doi.org/10.1259/bjr.20140627

[9] Seals, K.F., Lee, E.W., Cagnon, C.H., Al-Hakim, R.A. and Kee, S.T. (2016) Radiation-Induced Cataractogenesis: A Critical Literature Review for the Interventional Radiologist. Cardio Vascular and Interventional Radiology, 39, 151-160. https://doi.org/10.1007/s00270-015-1207-z

[10] Donadille, L., Carinou, E., Brodecki, M., et al. (2011) Staff Eye Lens and Extremity Exposure in Interventional Cardiology: Results of the ORAMED Project. Radiation Measurements, 46, 1203-1209. https://doi.org/10.1016/j.radmeas.2011.06.034

[11] Vañó, E., Miller, D.L. and Dauer, L. (2015) Implications in Medical Imaging of the New ICRP Thresholds for Tissue Reactions. Annals of the ICRP, 44, 118-128. https://doi.org/10.1177/0146645314562322

[12] Sánchez, R.M., Vano, E., Fernández, J.M., et al. (2016) Occupational Eye Lens Doses in Interventional Cardiology. A Multicentric Study. Journal of Radiological Protection, 36, 133-143. https://doi.org/10.1088/0952-4746/36/1/133

[13] Omar, A., Kadesjö, N., Palmgren, C., Marteinsdottir, M., Segerdahl, T. and Fransson, A. (2017) Assessment of the Occupational Eye Lens Dose for Clinical Staff in Interventional Radiology, Cardiology and Neuroradiology. Journal of Radiological 
Protection, 37, 145-159. https://doi.org/10.1088/1361-6498/aa559c

[14] Geber, T., Gunnarsson, M. and Mattsson, S. (2011) Eye Lens Dosimetry for Interventional Procedures-Relation between the Absorbed Dose to the Lens and Dose at Measurement Positions. Radiation Measurements, 46, 1248-1251. https://doi.org/10.1016/j.radmeas.2011.07.028

[15] Rivett, C., Dixon, M., Matthews, L. and Rowles, N. (2016) An Assessment of the Dose Reduction of Commercially Available Lead Protective Glasses for Interventional Radiology Staff. Radiation Protection Dosimetry, 172, 443-452. https://doi.org/10.1093/rpd/ncv540

[16] Fetterly, K., Schueler, B., Grams, M., Sturchio, G., Bell, M. and Gulati, R. (2017) Head and Neck Radiation Dose and Radiation Safety for Interventional Physicians. JACC: Cardiovascular Interventions, 10, 520-528. https://doi.org/10.1016/j.jcin.2016.11.026

[17] Cousin, A.J., Lawdahl, R.B., Chakraborty, D.P. and Koehler, R.E. (1987) The Case for Radioprotective Eyewear/Facewear. Practical Implications and Suggestions. Investigative Radiology, 22, 688-692. https://doi.org/10.1097/00004424-198708000-00012

[18] Magee, J.S., Martin, C.J., Sandblom, V., et al. (2014) Derivation and Application of Dose Reduction Factors for Protective Eyewear Worn in Interventional Radiology and Cardiology. Journal of Radiological Protection, 34, 811-823. https://doi.org/10.1088/0952-4746/34/4/811

[19] Koukorava, C., Farah, J., Struelens, L., et al. (2014) Efficiency of Radiation Protection Equipment in Interventional Radiology: A Systematic Monte Carlo Study of Eye Lens and Whole Body Doses. Journal of Radiological Protection, 34, 509-528. https://doi.org/10.1088/0952-4746/34/3/509

[20] Koukorava, C., Carinou, E., Simantirakis, G., et al. (2011) Doses to Operators during Interventional Radiology Procedures: Focus on Eye Lens and Extremity Dosimetry. Radiation Protection Dosimetry, 144, 482-486. https://doi.org/10.1093/rpd/ncq328

[21] Haussen, D.C., Van Der Bom, I.M. and Nogueira, R.G. (2016) A Prospective Case Control Comparison of the Zero Gravity System versus a Standard Lead Apron as Radiation Protection Strategy in Neuroendovascular Procedures. Journal of NeuroInterventional Surgery, 8, 1052-1055.

https://doi.org/10.1136/neurintsurg-2015-012038

[22] Marichal, D.A., Anwar, T., Kirsch, D., et al. (2011) Comparison of a Suspended Radiation Protection System versus Standard Lead Apron for Radiation Exposure of a Simulated Interventionalist. Journal of Vascular and Interventional Radiology, 22, 437-442. https://doi.org/10.1016/j.jvir.2010.12.016

[23] Savage, C., Seale, T., Shaw, C., Bruner, A., Marichal, D. and Rees, C. (2013) Evaluation of a Suspended Personal Radiation Protection System vs. Conventional Apron and Shields in Clinical Interventional Procedures. Open Journal of Radiology, 3, 143-151. https://doi.org/10.4236/ojrad.2013.33024

[24] Lichliter, A., Weir, V., Heithaus, R.E., et al. (2017) Clinical Evaluation of Protective Garments with Respect to Garment Characteristics and Manufacturer Label Information. Journal of Vascular and Interventional Radiology, 28, 148-155. https://doi.org/10.1016/j.jvir.2016.08.006

[25] Gipson, S., Weir, V., Sharafa, M. and Rees, C. (2017) The Effects of Attenuating Head Caps and Other Common Lead Equivalent Shields on Operator Brain Exposures in the Interventional Environment. Journal of Vascular and Interventional 
Radiology, 28, S183. https://doi.org/10.1016/j.jvir.2016.12.1049

[26] Pierno, J. and Hamilton, C. (2012) SU-E-I-35: Experience with the Zero Gravity Suit. Medical Physics, 39, 3633. https://doi.org/10.1118/1.4734750

[27] Ray, M.J., Mohammad, F., Taylor, W.B., Cura, M. and Savage, C. (2013) Comparison of Fluoroscopic Operator Eye Exposures When Working from Femoral Region, Side, or Head of Patient. Proceedings (Baylor University. Medical Center), 26, 243-246. https://doi.org/10.1080/08998280.2013.11928971

[28] Layton, K.F., Kallmes, D.F., Cloft, H.J., Schueler, B.A. and Sturchio, G.M. (2006) Radiation Exposure to the Primary Operator during Endovascular Surgical Neuroradiology Procedures. American Journal of Neuroradiology, 27, 742-743.

[29] Landauer. Product Specification File. Luxel ${ }^{\circledR}+$. https://www.landauer.com/sites/default/files/product-specification-file/Luxel\%2B_1 $\underline{\mathrm{pdf}}$

[30] Brateman, L. (1999) The AAPM/RSNA Physics Tutorial for Residents. RadioGraphics, 19, 1037-1055. https://doi.org/10.1148/radiographics.19.4.g99j1231037

[31] Schueler, B.A., Vrieze, T.J., Bjarnason, H. and Stanson, A.W. (2006) An Investigation of Operator Exposure in Interventional Radiology. Radiographics, 26, 1533-1541. https://doi.org/10.1148/rg.265055127

[32] Williams, J.R. (1997) The Interdependence of Staff and Patient Doses in Interventional Radiology. The British Journal of Radiology, 70, 498-503.

https://doi.org/10.1259/bjr.70.833.9227232

[33] Maeder, M., Brunner-La Rocca, H.P., Wolber, T., et al. (2006) Impact of a Lead Glass Screen on Scatter Radiation to Eyes and Hands in Interventional Cardiologists. Catheterization and Cardiovascular Interventions, 67, 18-23. https://doi.org/10.1002/ccd.20457

[34] Kuon, E., Günther, M., Gefeller, O. and Dahm, J.B. (2003) Standardization of Occupational Dose to Patient DAP Enables Reliable Assessment of Radiation-Protection Devices in Invasive Cardiology. Rofo, 175, 1545-1550.

https://doi.org/10.1055/s-2003-43412

[35] Zorzetto, M., Bernardi, G., Morocutti, G. and Fontanelli, A. (1997) Radiation Exposure to Patients and Operators during Diagnostic Catheterization and Coronary Angioplasty. Catheterization and Cardiovascular Diagnosis, 40, 348-351. https://doi.org/10.1002/(SICI)1097-0304(199704)40:4<348::AID-CCD4>3.0.CO;2-9

[36] Bor, D., Olgar, T., Onal, E., Caglan, A. and Toklu, T. (2009) Assessment of Radiation Doses to Cardiologists during Interventional Examinations. Medical Physics, 36, 3730-3736. https://doi.org/10.1118/1.3168971

[37] Antic, V., Ciraj-Bjelac, O., Rehani, M., Aleksandric, S., Arandjic, D. and Ostojic, M. (2013) Eye Lens Dosimetry in Interventional Cardiology: Results of Staff Dose Measurements and Link to Patient Dose Levels. Radiation Protection Dosimetry, 154, 276-284. https://doi.org/10.1093/rpd/ncs236

[38] Efstathopoulos, E.P., Pantos, I., Andreou, M., et al. (2011) Occupational Radiation Doses to the Extremities and the Eyes in Interventional Radiology and Cardiology Procedures. The British Journal of Radiology, 84, 70-77. https://doi.org/10.1259/bjr/83222759

[39] Dragusin, O., Weerasooriya, R., Jaïs, P., et al. (2007) Evaluation of a Radiation Protection Cabin for Invasive Electrophysiological Procedures. European Heart Journal, 28, 183-189. https://doi.org/10.1093/eurheartj/ehl420

[40] Servomaa, A. and Karppinen, J. (2001) The Dose-Area Product and Assessment of 
the Occupational Dose in Interventional Radiology. Radiation Protection Dosimetry, 96, 235-236. https://doi.org/10.1093/oxfordjournals.rpd.a006590

[41] Measurements NCRP (2009) Ionizing Radiation Exposure of the Population of the United States (NCRP Report No 160). Bethesda.

[42] Vano, E., Sanchez, R.M. and Fernandez, J.M. (2015) Estimation of Staff Lens Doses during Interventional Procedures. Comparing Cardiology, Neuroradiology and Interventional Radiology. Radiation Protection Dosimetry, 165, 279-283. https://doi.org/10.1093/rpd/ncv049

[43] Haga, Y., Chida, K., Kaga, Y., Sota, M., Meguro, T. and Zuguchi, M. (2017) Occupational Eye Dose in Interventional Cardiology Procedures. Scientific Reports, 7, Article No. 569. https://doi.org/10.1038/s41598-017-00556-3

[44] Prater, S., Rees, C.R., Bruner, A. and Savage, C. (2011) Determination of Minimum Effective Height of Transparent Radiation Face Shielding for Fluoroscopy. Health Physics, 101, S135-S141. https://doi.org/10.1097/HP.0b013e31821ec5bf

[45] Marshall, N.W., Faulkner, K. and Clarke, P. (1992) An Investigation into the Effect of Protective Devices on the Dose to Radiosensitive Organs in the Head and Neck. The British Journal of Radiology, 65, 799-802. https://doi.org/10.1259/0007-1285-65-777-799

[46] United States Nuclear Regulatory Commission (2016) Texas Administrative Code. Standards for Protection against Radiation from Radioactive Materials. TAC 289.202. https://www.nrc.gov/docs/ML1607/ML16076A372.pdf

[47] ICRP (1991) 1990 Recommendations of the International Commission on Radiological Protection. ICRP Publication 60. Annals of the ICRP, 21, 1-201. https://doi.org/10.1016/0146-6453(91)90066-P

[48] Chiriotti, S., Ginjaume, M., Vano, E., et al. (2011) Performance of Several Active Personal Dose Meters in Interventional Radiology and Cardiology. Radiation Measurements, 46, 1266-1270. https://doi.org/10.1016/j.radmeas.2011.05.073

[49] Bolch, W.E., Dietze, G., Petoussi-Henss, N. and Zankl, M. (2015) Dosimetric Models of the Eye and Lens of the Eye and Their Use in Assessing Dose Coefficients for Ocular Exposures. Annals of the ICRP, 44, 91-111. https://doi.org/10.1177/0146645314562320

[50] Allisy, A., Jennings, W.A., Kellerer, A.M. and Müller, J.W. (2016) Report 51. Journal of the International Commission on Radiation Units and Measurements, 26. https://doi.org/10.1093/jicru/os26.2.Report51

[51] Behrens, R. (2012) On the Operational Quantity H(p)(3) for Eye Lens Dosimetry. Journal of Radiological Protection, 32, 455-464. https://doi.org/10.1088/0952-4746/32/4/455 